\title{
Development and Validation of Vilazodone Hcl by Rp-Hplc In Bulk and in Pharmaceutical Formulation Along with its Application in Dissolution
}

\author{
Vivekkumar K Redasani ${ }^{*}{ }^{*}$, Sanjay J Surana ${ }^{1}$
}

R. C. Patel Institute of Pharmaceutical Education and Research, Karwand Naka, Shirpur, Dhule (MS) India 425405

Received:1 June, 2017; Accepted: 24 July, 2017; Published: 04 August, 2017

*Corresponding authors: Vivekkumar K Redasani, PhD, Associate Professor, R. C. Patel Institute of Pharmaceutical Education and Research, Karwand Naka, Shirpur, Dhule (MS) India, Tel: +919822027806, Fax: +912563255189; E-mail: vivek.redasani@gmail.com

\begin{abstract}
The aim of present work is to develop and validate accurate stability indicating RP-HPLC method for Vilazodone $\mathrm{HCl}$ in bulk drug and in tablets and the same is to be applied to dissolution. In RP-HPLC method, the drug was eluted from a Qualisil BDS C18 reversed phase column with methanol as mobile phase at a flow rate of $1 \mathrm{~mL} / \mathrm{min}$ $\mathrm{UV}$ detection at $242 \mathrm{~nm}$ and column temperature $30^{\circ} \mathrm{C}$. The retention time for Vilazodone $\mathrm{HCl}$ was found to be $3.5 \mathrm{~min}$. The linear response ( $\mathrm{r} 2=0.9987$ ) was observed in the range of $0.4-1.2 \mu \mathrm{g} / \mathrm{mL}$ with Limits of Detection (LOD) and Limits of Quantitation (LOQ) being 0.04 and $0.12 \mu \mathrm{g}$, respectively. The proposed method was validated across the several parameters in accordance with ICH guidelines. The stability indicating studies showed that drug undergoes slight degradation in acidic and basic conditions while it is stable against oxidative and photo degradation. As the method could affectively separate the drugs from their degradation products it can be employed as stability indicating method. In dissolution studies, the medium used is acetic acid PH 3.1 using a paddle apparatus at a stirring rate of $50 \mathrm{rpm}$. The drug release was evaluated by UV spectrophotometric method at $241 \mathrm{~nm}$ for Vilazodone $\mathrm{HCl}$. The method was validated to meet requirements for a global regulatory filing which includes linearity, precision, accuracy, robustness, sensitivity and ruggedness.
\end{abstract}

Keywords: Vilazodone HCl; RP-HPLC; validation; stability studies; dissolution; ICH guidelines

\section{Introduction}

Vilazodone $\mathrm{HCl}$ (VLN) is chemically 5-(4-[4-(5-cyano-1Hindol-3-yl) butyl] piperazin-1-yl) benzofuran-2-carboxamide hydrochloride [1] (Figure 1). It contains an indole piperazine that utilizes its function as an SSRI and 5-HT1a receptor partial agonist [2]. It belongs to the category of serotonergic antidepressant approved by FDA (Food and Drug Administration) for treatment of depressive disorder [3]. It is a serotonin reuptake inhibitor and serotonin $1 \mathrm{~A}$ receptor partial agonist having strong affinity for D2 dopaminergic receptors [4]. It has actions at several 5-HT (serotonin) receptor subtypes. The extensive literature review highlighted the therapeutic and pharmacological profile of drug but no published methods validated for its estimation in pharmaceutical formulations.

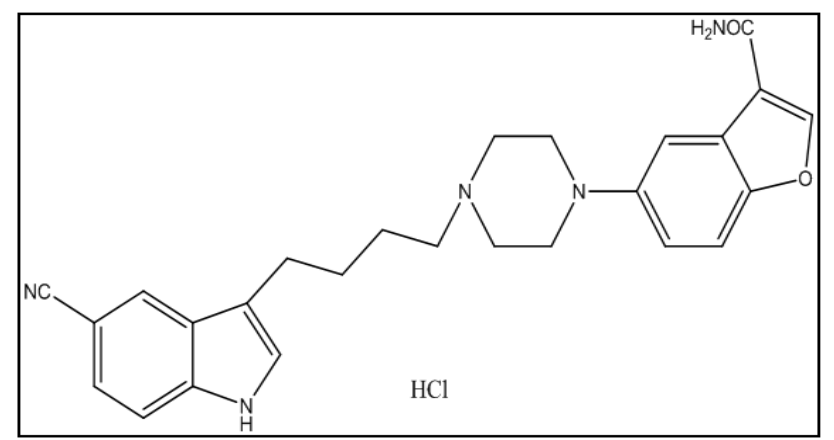

Figure 1: Chemical structure of Vilazodone $\mathrm{HCl}$

Dissolution test has emerged in the pharmaceutical field as a very important tool to characterize drug product performance. It provides measurements of the bioavailability of a drug as well as demonstrates bioequivalence from batch-to-batch. Besides, it is a requirement for regulatory approval for product marketing and is vital component of overall quality control programme.

In an attempt to assess the drug, recently we have published its estimation by spectroscopic method. In continuation to that, in the present study the same was applied for validation of dissolution test for quality control of Vilazodone $\mathrm{HCl}$ tablets. This encourages undertaking this work, so that quantitative estimation of VLN can be done and hence can be used for routine analysis of bulk and tablet formulation as well. The present study describes development and validation of rapid, simple, specific, sensitive, accurate and precise RP-HPLC Chromatographic methods for the determination of VLN in bulk and in tablet dosage form.

Dissolution methods, as well as other analytical methods, are validated to ensure that they are suitable for their intended 
use and give accurate and reliable data. Guidance on validation characteristics and considerations has been published. Validation of a dissolution method typically involves validation of the end analysis method for linearity, accuracy, precision, range, robustness and solution stability studies $[5,6]$.

\section{Materials and Methods}

\section{Materials}

Standard gift sample of Vilazodone $\mathrm{HCl}$ was provided by Glenmark Pharmaceuticals Ltd., Mumbai (India). Marketed tablets Viibryd (Forest laboratory Ltd.) were used for analysis as formulation. Methanol used for mobile phase is of HPLC grade and from Merck chem. Ltd., Mumbai (India). All reagents and solvents used were of analytical grade. Methanol and $0.01 \mathrm{M} \mathrm{HCl}$ of $\mathrm{pH} 2.0$, pH 3.1 acetic acid, $\mathrm{pH} 10.4$ phosphate buffer solutions were prepared according to USP Pharmacopoeia.

\section{Instrument}

The chromatographic analysis was performed on Shimadzu HPLC system equipped with PDA detector. The output signals were monitored and processed using LC Solution software. The analytical column was Qualisil BDS C18 (4.6 mm x $250 \mathrm{~mm}, 5 \mu$ ) and the samples were introduced through a Rheodyne injection valve with $20 \mu \mathrm{L}$ sample loop.

USP Standards tablet dissolution test multi-bath $(\mathrm{n}=6)$ apparatus form Electro lab, Model: TDT-06L was used for dissolution. The medium were vacuum degassed under in house vacuum and maintained at $37.0 \pm 0.5^{\circ} \mathrm{C}$ by using a thermostatic bath. A double-beam UV-Visible double beam spectrophotometer, make: SHIMADZU (model UV-2450) with a pair of $1 \mathrm{~cm}$ matched quartz cells with spectral band width of $1 \mathrm{~nm}$, was used for all absorbance measurements. Systronics pH system (Model: 362) was used to determine the $\mathrm{pH}$ of all solutions.

\section{Methods}

Determination of Vilazodone $\mathrm{HCl}$ in Bulk and in Tablet Formulation by RP-HPLC Detection of wavelength

The drug was accurately weighed $10 \mathrm{mg}$ and transferred in $100 \mathrm{~mL}$ volumetric flask, methanol was added up to the mark. From that solution $0.3 \mathrm{~mL}$ was pipette out and diluted with methanol in $10 \mathrm{~mL}$ volumetric flask. The scanning was done between 200-400nm by UV spectroscopy.

\section{Chromatographic conditions}

After performing number of trials by changing the mobile phase composition in various proportions and $\mathrm{pH}$ of buffer, finally methanol was selected as mobile phase that gives symmetrical peak. Injection volume was $20 \mu \mathrm{L}$, flow rate was $1.0 \mathrm{~mL} / \mathrm{min}$ and the eluent was detected at $242 \mathrm{~nm}$ at column temperature $30^{\circ} \mathrm{C}$. The retention time of VLN was obtained at $3.58 \mathrm{~min}$, showing a sharp peak. The total run time of analysis was less than $10 \mathrm{~min}$. The chromatogram of Vilazodone $\mathrm{HCl}$ is shown in Figure 2.

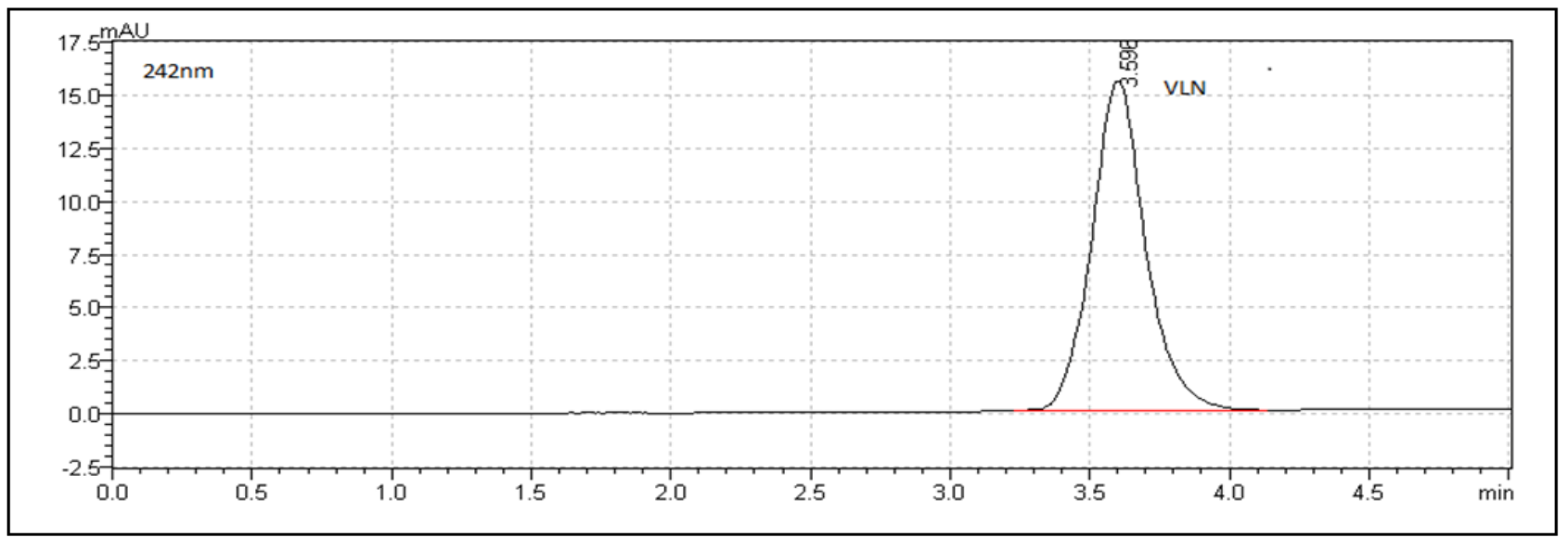

Figure 2: Chromatogram of Vilazodone $\mathrm{HCl}$ showing retention time $3.58 \mathrm{~min}$

\section{Preparation of stock and standard solution}

Standard stock solution was prepared by dissolving $10 \mathrm{mg}$ of VLN in $100 \mathrm{~mL}$ methanol that gives concentration of $100 \mu \mathrm{g} / \mathrm{mL}$. This solution was diluted with mobile phase as needed to prepare different standard solutions.

\section{Validation of proposed method}

The proposed method was validated as per ICH guidelines across several parameters like linearity, precision, accuracy, robustness, ruggedness and system suitability test $[7,8]$.

\section{Linearity}

From the stock solution of VLN aliquots of $0.4,0.6,0.8,1.0$ 1.2 , and $1.4 \mathrm{~mL}$ were taken in $10 \mathrm{~mL}$ volumetric flasks and diluted up to the mark with mobile phase to get the final concentration in range of $0.4-1.4 \mu \mathrm{g} / \mathrm{mL}$. Calibration curve was constructed by plotting the peak area vs. the drug concentration.

\section{Precision}

Precision can be performed at two different levelsrepeatability and intermediate precision. Repeatability refers to 
the use of the analytical procedure within the laboratory over the shorter period of the time that was evaluated by assaying the samples during the same day. Repeatability was carried out using six replicates of the sample injection.

Intra-day precision was determined by analyzing, the three different concentrations $0.4,0.6$ and $0.8 \mu \mathrm{g} / \mathrm{mL}$. of VLN, for three times in the same day. Day to day variability was assessed using above mentioned three concentrations analyzed on three consecutive days for inter day precision.

\section{Accuracy}

Accuracy was done by recovery study using standard addition method at $80 \%, 100 \%$ and $120 \%$ level; known amount of standard VLN was added to the sample and subjected to the proposed HPLC method. The accuracy studies were carried out three times and the \% recovery and \% RSD was calculated.

\section{Limit of Detection (LOD) and Limit of Quantitation (LOQ)}

Sensitivity of the proposed method was estimated in terms of LOD and LOQ. LOD is the lowest concentration in a sample that can be detected, but not necessarily quantified; under the stated experimental conditions. LOQ is the lowest concentration of analytes in a sample that can be determined with acceptable precision. In order to determine LOD and LOQ, VLN concentrations in the lower part of the linear range of the calibration curve was used. Dilutions of $0.4,0.6,0.8,1.0$, and $1.2 \mu \mathrm{g} / \mathrm{mL}$ were prepared for analysis.

\section{Application of proposed method marketed tablets}

Twenty tablets, each containing $10 \mathrm{mg}$ VLN, were accurately weighed and finely powdered. A quantity equivalent to $10 \mathrm{mg}$ of VLN was transferred to $100 \mathrm{~mL}$ volumetric flask and diluted using methanol. The resulting solution was filtered using $0.45 \mu \mathrm{m}$ filter. It was further diluted for analysis to get a concentration of $1.2 \mu \mathrm{g} / \mathrm{mL}$. The proposed method was validated in accordance with ICH guidelines.

\section{Robustness}

Robustness of the method was studied by making small deliberate changes in few parameters. The flow rate and mobile phase composition were varied by $\pm 0.2 \mathrm{~mL} / \mathrm{min}$ and $\pm 5 \%$, respectively. The effects on the results were studied by injecting $0.8 \mu \mathrm{g} / \mathrm{mL}$ of VLN.

\section{Ruggedness}

From stock solution, sample solution of VLN $(0.8 \mu \mathrm{g} / \mathrm{mL})$ was prepared and analyzed by two different analysts using similar operational and environmental conditions. Peak area was measured for same concentration solutions, six times.

\section{System Suitability Test}

System suitability testing is essential for the assurance of the quality performance of chromatographic system. Earlier prepared solutions for chromatographic conditions were tested for system suitability testing.

\section{Forced degradation studies}

Initially $10 \mathrm{mg}$ VLN was kept in $0.1 \mathrm{~N} \mathrm{HCl}, 0.1 \mathrm{~N} \mathrm{NaOH}$ and $3 \% \mathrm{H}_{2} \mathrm{O}_{2}(10 \mathrm{~mL}$ each), at room temperature. Simultaneously, $10 \mathrm{mg}$ of VLN was exposed to direct sunlight for $12 \mathrm{hr}$. The drug was exposed to higher conditions in gradual increasing manner. Finally an intentional degradation was carried out by refluxing $10 \mathrm{mg}$ of VLN in $10 \mathrm{~mL} 1 \mathrm{~N} \mathrm{HCl}$ and $1 \mathrm{~N} \mathrm{NaOH}$; while $10 \mathrm{mg}$ drug was dissolved in $30 \% \mathrm{H}_{2} \mathrm{O}_{2}$ and kept for $24 \mathrm{hr}$. Exposure time to direct sunlight was increased up to $24 \mathrm{hr}$. Acidic and basic samples were neutralized and $20 \mu \mathrm{L}$ of sample solutions were injected and analyzed [9].

\section{Application of proposed method to dissolution study}

\section{Solubility determination and dissolution test optimization}

The solubility of Vilazodone $\mathrm{HCl}$ was determined in 1000 $\mathrm{mL}$ of $0.01 \mathrm{M} \mathrm{HCl}$, pH 3.1 acetic acid, pH 10.4 phosphate buffer using an amount of the drug equivalent to three times of dose in the pharmaceutical formulation [10]. Drug release tests were carried out according to conventional dissolution procedures recommended for single entity products, using paddle (USP Apparatus II) at $50 \mathrm{rpm}$.

\section{Dissolution study of Vilazodone HCl tablets using absorbance method}

The release kinetics of VLN from tablets was studied by conducting dissolution tests. Dissolution tests were performed using (USP Apparatus II) dissolution apparatus and $1000 \mathrm{~mL}$ of $\mathrm{pH} 3.1$ acetic acid as dissolution medium at $37 \pm 0.5^{\circ} \mathrm{C}$ at $50 \mathrm{rpm}$ [11]. Sampling aliquots of $10 \mathrm{~mL}$ were withdrawn at $0,5,10,15$, $20,30,45,60$ and $75 \mathrm{~min}$ and replaced with an equal volume of the fresh medium. The absorbance of solution was recorded at $241 \mathrm{~nm}$ using pH 3.1 acetic acid dissolution medium as blank and drug release was calculated.

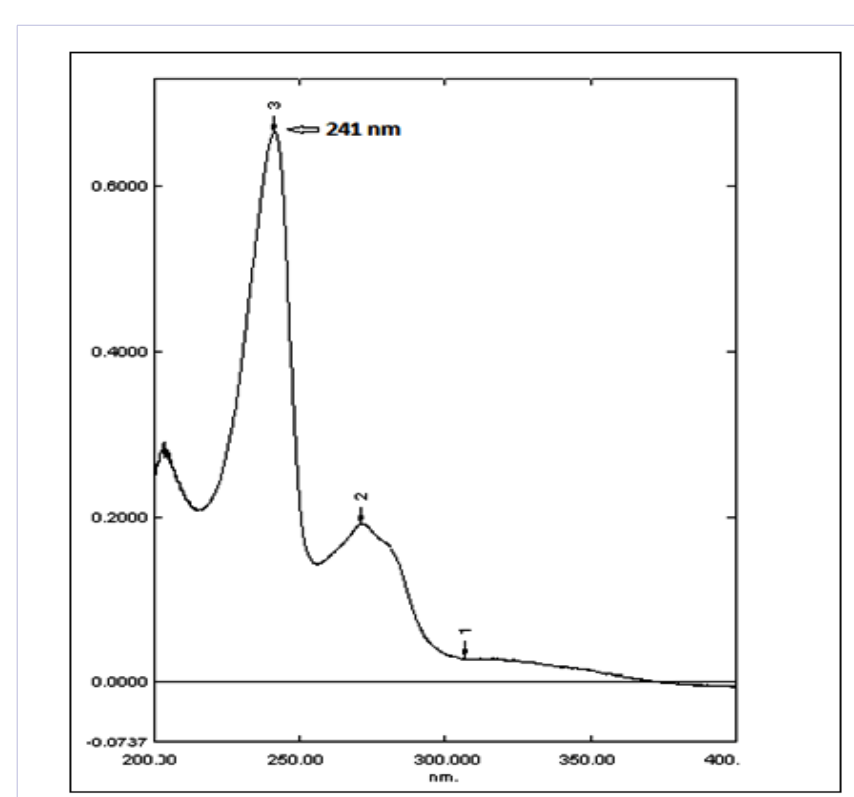

Figure 3: UV absorbance spectra of Vilazodone $\mathrm{HCl}$ showing $\lambda$ max at $241 \mathrm{~nm}$ 


\section{Linearity}

The linearity of drug response is evaluated in the range of 1-5 $\mu \mathrm{g} / \mathrm{mL}$ and showed a good correlation coefficient. To assess linearity, the standard curves of VLN was constructed by plotting concentration $(\mu \mathrm{g} / \mathrm{ml})$ vs absorbance as shown in Figure 4.

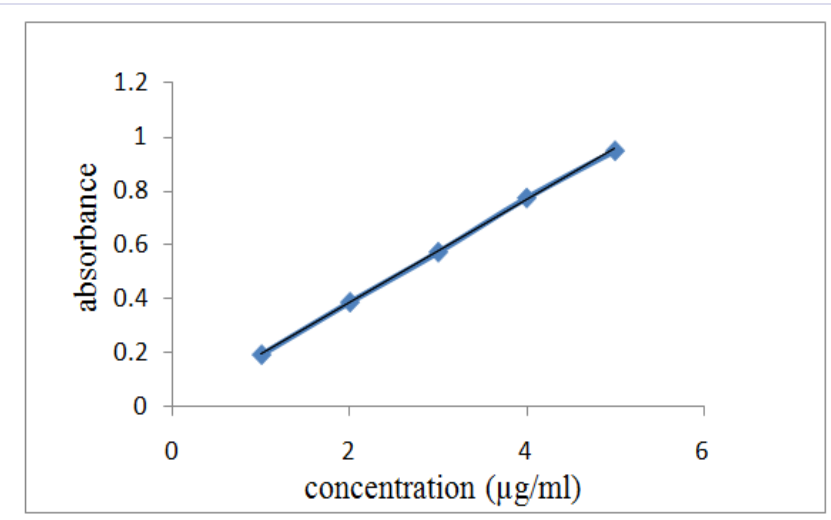

Figure 4: Calibration curve of Vilazodone $\mathrm{HCl}$

\section{Precision}

Precision of the method was studied as intra-day and interday variations. Intra-day precision was determined by analyzing 2,3 and $4 \mu \mathrm{g} / \mathrm{mL}$ of solution for three times in the same day. Interday precision was determined by analyzing same concentration daily for three consecutive days over a period of week.

\section{Accuracy (Recovery studies)}

Accuracy was evaluated by applying proposed method to the analysis of mixture of the tablet and with known amount of working standard, corresponding to the concentrations of 80 , 100 and $120 \%$.

\section{Repeatability}

Repeatability was determined by analyzing $3 \mu \mathrm{g} / \mathrm{mL}$ concentration of solution for six times. The absorbance of solution was recorded and spectra were recorded.

\section{Sensitivity}

Sensitivity of the proposed method was estimated in terms of Limit of Detection (LOD) and Limit of Quantitation (LOQ). The LOD and LOQ were calculated by the use of equation,

$$
\mathrm{LOD}=\mathrm{SD} / \mathrm{S} \times 3.3 \text { and LOQ }=\mathrm{SD} / \mathrm{S} \times 10,
$$

\section{Where}

SD is the residual standard deviation of the peak areas of the $\operatorname{drug}(n=6)$.

'S' is the slope of the line. Sensitivity was performed between $2-3 \mu \mathrm{g} / \mathrm{mL}$, for method.

\section{Ruggedness}

Ruggedness of the proposed method was determined by analysis of from homogenous slot by two different analysts using same operational and environmental conditions.

\section{Results and Discussion}

Method A: Determination of Vilazodone $\mathrm{HCl}$ in Bulk and in Tablet Formulation by RP-HPLC

A simple, accurate, precise and specific stability indicating RP-HPLC method for estimation of Vilazodone $\mathrm{HCl}$ using stressed samples, various mobile phases with different composition and flow rate were tried. After several permutation and combinations, chromatographic condition has been optimized and established. Satisfactory estimation of VLN with good peak symmetry and steady baseline was obtained with the mobile phase methanol at a flow rate of $1.0 \mathrm{~mL} / \mathrm{min}$. Drug showed single sharp peak at retention time (RT) of 3.58 min with clear baseline at $242 \mathrm{~nm}$. The detail validation parameters are summarized in Table 1. The standard curve for VLN was linear over the investigated concentration range $0.2-1.0 \mu \mathrm{g} / \mathrm{mL}$.

\begin{tabular}{|c|c|c|c|c|}
\hline Parameters & $\begin{array}{c}\text { Conc. } \\
(\mu \mathrm{g} / \mathrm{mL})\end{array}$ & $\begin{array}{l}\text { Amt. found } \\
(\mu \mathrm{g}) \\
\text { Mean } \pm \text { S.D. }\end{array}$ & \% R.S.D. & $\begin{array}{c}\% \\
\text { Recovered }\end{array}$ \\
\hline \multicolumn{5}{|l|}{ Precision } \\
\hline \multirow{3}{*}{$\begin{array}{l}\text { Intra-day } \\
(\mathrm{n}=3)\end{array}$} & 0.4 & $0.40 \pm 0.021$ & 1.24 & - \\
\hline & 0.6 & $0.60 \pm 0.021$ & 0.03 & - \\
\hline & 0.8 & $0.79 \pm 0.022$ & 0.73 & - \\
\hline \multirow{3}{*}{$\begin{array}{l}\text { Inter-day } \\
(\mathrm{n}=3)\end{array}$} & 0.4 & $0.40 \pm 0.002$ & 1.23 & - \\
\hline & 0.6 & $0.60 \pm 0.008$ & 0.60 & - \\
\hline & 0.8 & $0.79 \pm 0.015$ & 0.57 & - \\
\hline \multicolumn{5}{|c|}{ Recovery studies } \\
\hline $80 \%$ & 0.4 & $0.71 \pm 0.029$ & 1.86 & 99.34 \\
\hline $100 \%$ & 0.4 & $0.79 \pm 0.040$ & 0.11 & 98.87 \\
\hline $120 \%$ & 0.4 & $0.87 \pm 0.012$ & 0.63 & 99.59 \\
\hline Tablet assay & 0.8 & $0.81 \pm 0.020$ & 1.29 & 101.61 \\
\hline \multicolumn{5}{|l|}{ Ruggedness } \\
\hline Analyst I & 0.8 & $0.81 \pm 0.012$ & 1.46 & 99.51 \\
\hline Analyst II & 0.8 & $0.80 \pm 0.016$ & 1.32 & 100.04 \\
\hline
\end{tabular}




\section{Precision}

The precision of an analytical method is the degree of agreement among individual test results obtained when the method is applied to multiple sampling of a homogenous sample. Precision studies of proposed method were determined by repeatability and intermediate precision (intra-day and inter-day precision). Repeatability was measured by multiple injections of $0.8 \mu \mathrm{g} / \mathrm{mL}$ of VLN that indicates the performance of the HPLC instrument under chromatographic conditions. The \% RSD was found to be within the limit indicating the proposed method is more precise.

\section{Recovery}

The mean recovery data of VLN in sample was $100.03 \%$, while $\%$ RSD was 0.71 , that satisfying the acceptance criteria for the study. It proved that there is no interference of excipients used in tablet.

\section{Limit of detection (LOD) and Limit of Quantitation (LOQ)}

The LOD with signal-to-noise (S/N) ratio of 3:1 and the LOQ with S/N ratio of 10:1 were calculated for VLN using the equations

\section{$L O D=3.3 \times N / B$ and $L O Q=10 \times N / B$}

Where

' $N$ ' is the standard deviation of the peak areas of the drug $(n=3)$, taken as measure of the noise

' $\mathrm{B}$ ' is the slope of corresponding calibration plot.

The signal to noise ratio was determined. LOD and LOQ were found to be 0.15 and $0.47 \mu$ g respectively.

\section{Tablet assay}

By taking the average of six determinations, the amount found for VLN was $101.61 \%$. From the data obtained, \% RSD of drug was found to be within the limits, thus it can be concluded that excepients do not interfere.

\section{Robustness}

The robustness of the proposed method was studied by introducing small deliberate changes in flow rate $\pm \pm 0.2 \mathrm{~mL} /$
Table 2: Robustness of the proposed method

\begin{tabular}{|c|c|c|c|c|c|}
\hline Runs & $\begin{array}{c}\text { Temperature } \\
\left( \pm 0.5^{\circ} \mathrm{C}\right)\end{array}$ & $\begin{array}{c}\text { Flow rate } \\
( \pm 0.2 \mathrm{~mL} / \\
\mathrm{min})\end{array}$ & Area & $\begin{array}{c}\text { Retention } \\
\text { time } \\
\text { (min) }\end{array}$ & $\begin{array}{c}\text { Tailing } \\
\text { factor }\end{array}$ \\
\hline 1 & 29.5 & 0.8 & 1.182640 & 3.28 & 1.14 \\
\hline 2 & 29.5 & 1.2 & 0.948374 & 3.47 & 1.17 \\
\hline 3 & 30 & 1.0 & 0.505412 & 3.57 & 1.05 \\
\hline 3 & 30.5 & 1.2 & 0.797948 & 3.78 & 1.19 \\
\hline 4 & 30.5 & 0.8 & 1.178875 & 3.20 & 1.20 \\
\hline
\end{tabular}

$\min )$ and temperature $\left( \pm 0.5^{\circ} \mathrm{C}\right)$. With respect to these, changes in retention time and tailing factor were observed and the detail results are tabulated in Table 2 .

\section{Recovery}

Ruggedness of the method was studied by two different analysts. Method proved to be rugged as it showed low values of $\%$ RSD.

\section{System suitability test}

The number of theoretical plates and other system suitability parameters were calculated, and were found to be within the limits.

\section{Degradation studies}

After exposing the drug to different degradation conditions like acidic, alkaline and oxidation, a single peak of degradation sample was found in acidic and alkaline conditions with less amount of degradent. Finally, VLN was refluxed with $1 \mathrm{~N} \mathrm{NaOH}$ and $1 \mathrm{~N} \mathrm{HCl}$ at $60^{\circ} \mathrm{C}$ for $3 \mathrm{hr}$; drug was kept in $30 \% \mathrm{H} 2 \mathrm{O} 2$ at room temperature for $24 \mathrm{hr}$ and $10 \mathrm{mg}$ of VLN was exposed to sunlight for $24 \mathrm{hr}$ ( $6 \mathrm{hr}$ per day). This stress study gives a single peak of degrade in acidic and alkaline conditions with increased amount of degrade. This indicates that the drug is unstable at acidic and alkaline condition. This fact also gives an additional advantage in designing the formulation across the shelf life of VLN (Figure 5 and 6) (Table 3).

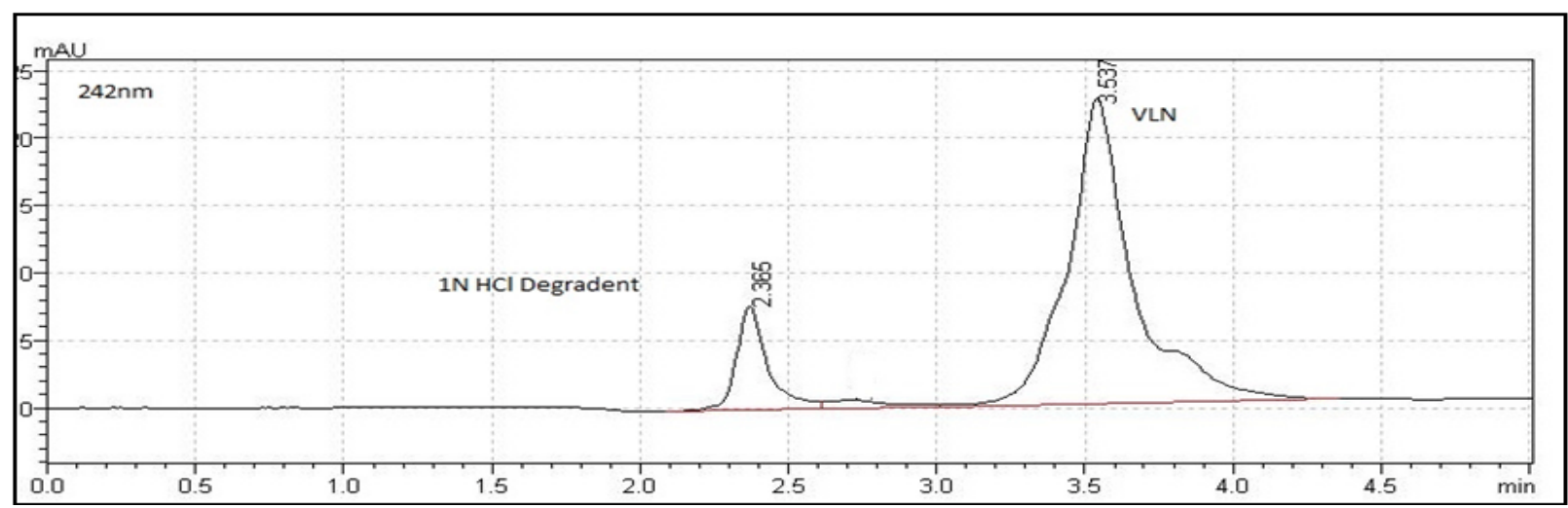

Figure 5: Chromatogram of Vilazodone $\mathrm{HCl}$ Degradation in $1 \mathrm{~N} \mathrm{HCl}$ 


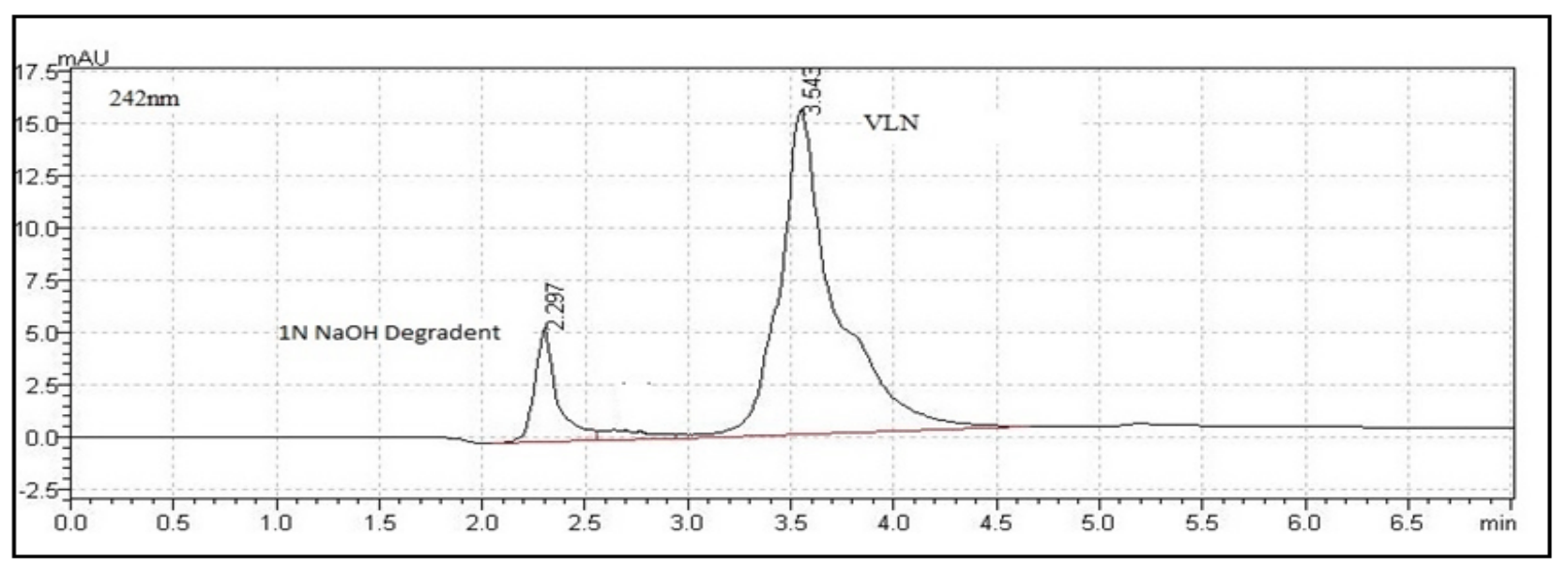

Figure 6: Chromatogram of Vilazodone $\mathrm{HCl}$ Degradation in $1 \mathrm{~N} \mathrm{NaOH}$

Table 3: Forced degradation study

\begin{tabular}{|c|c|c|c|c|c|}
\hline Agent & Exposure time & Conditions & No. of Degradant peak & RT (min) & \% Degradation \\
\hline $1 \mathrm{~N} \mathrm{HCl}$ & $3 \mathrm{hr}$ & $60^{\circ} \mathrm{C}$ (Reflux) & 1 & 2.35 & 18.60 \\
\hline $1 \mathrm{~N} \mathrm{NaOH}$ & $3 \mathrm{hr}$ & $60^{\circ} \mathrm{C}$ (Reflux) & 1 & 2.37 & 17.55 \\
\hline $30 \% \mathrm{H}_{2} \mathrm{O}_{2}$ & $24 \mathrm{hr}$ & - & - & - & - \\
\hline Light & $24 \mathrm{hr}$ & Sunlight & - & - & - \\
\hline
\end{tabular}

\section{Method B: Application of proposed method to} dissolution study

For dissolution test method the conditions that allowed the dissolution are $1000 \mathrm{~mL} \mathrm{pH} 3.1$ acetic acid $37.0 \pm 0.5^{\circ} \mathrm{C}$ paddle apparatus, $50 \mathrm{rpm}$ stirring speed. The in vitro dissolution profiles in different physiological $\mathrm{pH}$ mediums at higher speed i.e. $50 \mathrm{rpm}$, the drug release is more compared to that at 25 . This is because of the less solubility of the Vilazodone across all medium. The $\mathrm{pH}$ 3.1 shows the faster and completes dissolution, indicates that the drug is to be given with food, to have maximum effect, as the $\mathrm{pH}$ of the stomach is around 3 to 4.5 under FED condition. The in vitro dissolution data showed the release was found to be almost $95 \%$ at the end of $75 \mathrm{~min}$. The results are tabulated in Table 4 and the release pattern is shown in Figure 7

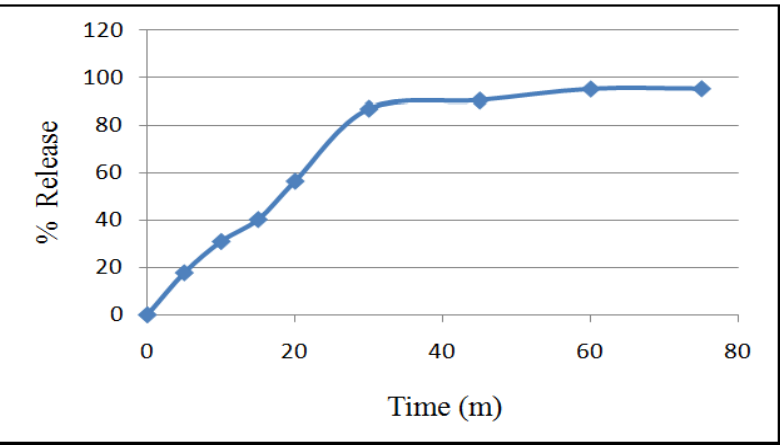

Figure 7: In vitro drug release pattern of Vilazodone $\mathrm{HCl}$
Table 4: In vitro drug release data of Vilazodone $\mathrm{HCl}$

\begin{tabular}{|c|c|c|c|}
\hline Sr. No & $\begin{array}{c}\text { Sampling } \\
\text { Time (min) }\end{array}$ & $\begin{array}{c}\text { Absorbance of } \\
\text { Vilazodone HCl }\end{array}$ & $\begin{array}{c}\text { Percentage release of } \\
\text { Vilazodone HCl }\end{array}$ \\
\hline 1 & 0 & 0 & 0 \\
\hline 2 & 5 & 0.112 & 17.81 \\
\hline 3 & 10 & 0.171 & 13.06 \\
\hline 4 & 15 & 0.212 & 40.36 \\
\hline 5 & 20 & 0.284 & 56.58 \\
\hline 6 & 30 & 0.419 & 97.11 \\
\hline 7 & 45 & 0.435 & 90.57 \\
\hline 8 & 60 & 0.455 & 95.23 \\
\hline 9 & 75 & 0.456 & 95.30 \\
\hline
\end{tabular}

In this method Vilazodone $\mathrm{HCl}$ followed linearity in concentration range $1-5 \mu \mathrm{g} / \mathrm{ml}$. The developed methods were applied for pharmaceutical tablet formulations. The \% amount of Vilazodone $\mathrm{HCl}$ from tablet formulation was found to be 98.32 $\%$. Precision study at different time and day interval in method showed low standard deviation and \% RSD less than 2 indicate that the proposed methods are precise for determination of Vilazodone $\mathrm{HCl}$. High recovery and low standard deviation confirmed that proposed method is accurate for its determination in pharmaceutical tablet formulation. The method was found to be rugged as indicated by low value of $\%$ RSD. Results obtained for 
LOD and LOQ is a sign of adequate sensitivity of the method. The detailed results showing summary of all validation parameters of proposed methods are tabulated in Table 5. Thus, the method was found to be simple, economical and can suitably apply for the routine analysis of Vilazodone $\mathrm{HCl}$ in pharmaceutical tablet formulation.

Table 5: Summary of validation parameter for method B

\begin{tabular}{|c|c|}
\hline Parameters & Results \\
\hline Linearity $(\mu \mathrm{g} / \mathrm{ml})$ & $1-5$ \\
\hline $\mathrm{Y}=\mathrm{mx}+\mathrm{C}$ & $\mathrm{Y}=0.1895 \mathrm{x}+0.0063$ \\
\hline Correlation coefficient & 0.9996 \\
\hline LOD $(\mu \mathrm{g} / \mathrm{ml})$ & 0.112 \\
\hline LOQ $(\mu \mathrm{g} / \mathrm{ml})$ & 0.341 \\
\hline \% Recovery* & 99.82 \\
\hline \% RSD (Recovery) & 0.14 \\
\hline \multicolumn{2}{|c|}{ Precision (\% RSD) } \\
\hline Intra- Day* & $0.45-0.71$ \\
\hline Inter- Day* & $0.42-0.74$ \\
\hline Repeatability\# & 1.05 \\
\hline \multicolumn{2}{|c|}{ Ruggedness (\% RSD) \# } \\
\hline Analyst I & 1.02 \\
\hline Analyst II & 1.50 \\
\hline \multirow{2}{*}{$\#=3 n=6$} & \\
\hline
\end{tabular}

\section{Conclusion}

A validated stability indicating RP-HPLC method has been developed for the determination of VLN in bulk and in tablet dosage form. The proposed method is found to be simple, rapid, accurate and precise. The statistical evaluation of the proposed method was revealed its good linearity and its validation for different parameters and let us to the conclusion that it could be used for the rapid and reliable determination of VLN in tablet formulation. The modalities adopted in experiment were successfully validated as per ICH guidelines, analytical procedures laid down in routine analysis. The proposed method was validated by preliminary analysis of standard sample and by recovery studies. From the results obtained, it concluded that the method is suitable for estimation of Vilazodone $\mathrm{HCl}$. The dissolution study of Vilazodone HCl by UV-Spectroscopy has been done and the dissolution study shows that the drug release at 75 min up to $95 \%$, which is according to ICH guidelines, hence it can be used for tablet formulation. Therefore the proposed method was successfully applied and suggested for the quality control studies of Vilazodone $\mathrm{HCl}$ in tablet dosage forms contributing to assure the therapeutic efficacy of the drug.

\section{Acknowledgement}

The authors are thankful to Glenmark Pharmaceutical Ltd. Mumbai (India) for giving gift sample of Vilazodone $\mathrm{HCl}$.

\section{References}

1. Neil Maryadele JO. The Online Merck Index. 15th ed. Editor Merck and Co, White House Station, NJ, USA, 2006, Monograph no.MONO1500010176.

2. Hughes ZA, Starr KR, Langmead CJ, Hill M, Bartoszyk GD, Hagan J, et al. Neurochemical evaluation of the novel 5-HT1A receptor partial agonist/serotonin reuptake inhibitor, vilazodone. Eur J Pharmacol. 2005;510(1-2):49-57.

3. Khan A, Cutler AJ, Kajdasz DK, Gallipoli S, Athanasiou M, Robinson DS, et al. A randomized, double-blind, placebo-controlled, 8-week study of vilazodone, a serotonergic agent for the treatment of major depressive disorder. J Clin Psychiatry. 2011; 72(4):441-447. doi: 10.4088/ JCP.10m06596

4. Dawson LA, Watson JM. Vilazodone: A 5HT1a receptor agonist/ serotonin transporter inhibitor for treatment of affective disorders. CNS Neurosci Ther. 2009;15(2):107-117.

5. Sean JS, Alex MO, Beverly NA, Hong JJ, Monica DA, Mark BR. Validation of a dissolution method with HPLC analysis for lasofoxifene tartrate low dose tablets. J Pharm Biomed Anal. 2007;44(5):1064-1071.

6. Berry MR, Likar MD. Statistical assessment of dissolution and drug release profile similarity using a model-dependent approach. J Pharm Biomed Anal. 2007;45(2):194-200.

7. International conference on harmonization (ICH), Q2B: Validation of analytical procedure: Methodology, USFDA federal register. 1997.

8. International Conference on Harmonization (ICH), Q2A: Text on Validation of Analytical Procedure USFDA federal register. 1995.

9. Singh R, Rehman Z. Current trends in forced degradation study for pharmaceutical product development. J Pharm Educ Res. 2012;3(1):54-63.

10. United States Pharmacopoeia, 31, United States Pharmacopoeial Convention, Rockville, USA, 1776, 2007.

11. Instruction Manual model TDT-06L USP Standards Dissolution test apparatus. 